\title{
Colonization of Maltese Catacombs by Phototrophic Biofilms. How Much Does Light Matter?
}

\author{
E. Llop a, *, I. Alvaro a, M. Hernández-Mariné b, S. Sammut c, A. Gómez-Bolea a
}

\begin{abstract}
a Dpt. Plant Biology, University of Barcelona. Avda. Diagonal 64308024 Barcelona, Spain - ellv66@gmail.com,malvaro@ub.edu, agomez@ub.edu

b Dpt. Natural Products, Plant Biology and Edaphology, University of Barcelona, Joan XXIII 27-31 08028 Barcelona, Spain marionahernandez@ub.edu

c National Museum of Natural History, Vilhena Palace St Publius Square Mdina MDN 1011, Malta - stephanie.a.sammut@gov.mt
\end{abstract}

KEY WORDS: cyanobacteria, diatoms, green algae, red algae, distribution, species richness

\begin{abstract}
:
The study of phototrophic biofilms from Maltese catacombs has shown that their distribution within catacombs does not show a significant dependence on orientation of catacomb and their location inside the catacombs. A decrease on species richness is observed when light availability diminishes, but the composition of biofilms does not change significantly. The proportion of green algae has a slight increase in darker areas, while cyanobacteria remain stable and diatoms decrease. Diatoms are almost not present in deeper areas inside catacombs. However, light is not the only key factor driving the colonization by phototrophic biofilms.
\end{abstract}

\section{INTRODUCTION}

Hypogeal structures, either natural or man-made, encompass very peculiar environments with steady conditions in terms of temperature and humidity, but with restrains in nutritional aspects; consequently, they host specific communities which are well adapted to such conditions. Among those communities, phototrophic biofilms are affected not only by temperature and water availability, but also by light conditions.

Phototrophic organisms forming biofilms are able to colonize hypogeal sites where light is available, mainly entrances and nearby areas (Hernández-Mariné et al., 1999; Roldán et al., 2004; Albertano et al., 2005). Their extension inside hypogea depends on light extinction, which varies daily and seasonally. Furthermore, colonization of stone surfaces is thrived by substrate bioreceptivity (Guillitte, 1995; Warscheid \& Braams, 2000). Once a community is established it has to deal with the limiting conditions generated in subterranean sites (OrtegaCalvo et al., 1995).

New aspects arise when natural or man-made hypogea are conditioned by making them accessible to visitors. Installation of artificial light together with the presence of visitors modifies the original conditions further promoting the colonization of phototrophic biofilms. These organisms compete with preexisting heterotrophic and lithotrophic communities (Sanchez-Moral et al., 2005), thereby altering the equilibrium between preexistent organisms and substrate resulting in an increase in biodeterioration. In addition, we do not expect to have the same composition of phototrophic biofilms colonizing new areas at a greater depth within the sites, compared with the established communities at the entrance or nearby. The main difference lies on light irradiated from bulbs or any artificial source which is different from sun radiation. Therefore, we expect changes in specific composition as well as in abundance of species between communities thriving on natural light or on artificial light (Mulec et al., 2008).

Previous studies on Maltese hypogea have provided data from the diversity on biofilms (Zammitt et al., 2011a) and how they affect artworks present on those sites (Zammitt et al., 2011b). We have focused on the catacombs of St Paul and St Agatha, located in Rabat. The two catacombs areas were opened to visitors in the middle of 20th century, while the remnants catacombs remained closed and only occasionally visited for research purposes. The possibility to study all the catacombs has allowed us to compare the colonization by biofilms on areas with natural light from areas with artificial light.

The aim of our study was to check phototrophic biofilms from all the areas that looked colonized and compare if there were some differences in the composition of biofilms growing on artificial and natural light.

\section{MATERIAL AND METHODS}

The site consists of two large areas normally called St Paul's and SS Paul/Agatha, consisting of more than 30 hypogea. The main complex, situated within the St Paul's cluster, comprises a complex system of interconnected passages and tombs of an area of well over $2.000 \mathrm{sq}, \mathrm{m}$. While catacombs at St Paul's area have been visited since the middle of 20th century; the catacombs in SS Paul/Agatha area have not been visited, except for research purposes.

For each catacomb several sampling points have been selected, extending from the entrance to the deepest part reached by natural light and where colonization was observed. We tried to measure PAR for sample but the punctual measures do not compile the variation experimented through the day and the year. Therefore, we have categorized the environmental data

\footnotetext{
* Corresponding author.
} 
related to light according to the distance from the entrance into three different levels: entrance, inner hall and dark areas (where only artificial light was the light source). We have also considered the orientation of catacomb entrances, as will affect the light coming inside during the day and along the year. Apart from the points inside Catacombs in St Paul's area, labeled as artificially illuminated, the orientation has been referred to as north, east, south and west.

The identification of components of phototrophic biofilms was carried after sampling minute portions of substrate and culturing the samples. Cyanobacteria were cultured in BG11 culture medium, which is a successfully medium, used for most cyanobacteria. Green algae were cultured in a Bold's basal medium (BBM), a highly enriched medium.

Samples were examined using light and confocal laser scanning microscope (CLSM). The samples in light microscope were visualized using an Axioplan microscope equipped with an MRc5 AxioCam photomicrographic system. Cell measurements were made based on the optical images from field and cultured material. Characteristics previously considered as taxonomically important at generic and specific levels were considered. Samples from CLSM were observed in vivo. Images were captured with a Leica TCS-SP5 CLSM using PlanApochromatic 63x (NA 1.4, oil) objectives with different zoom ranges.

Data were processed statistically for differences of the diversity based on main taxonomic groups (cyanobacteria, diatoms, green algae and red algae) and total species richness present in phototrophic biofilms between light source, orientation of the entrance of catacombs and the location of sample inside reach catacomb. Data was found to fulfill requirements normality and homogeneity of variance for cyanobacteria, diatoms, green algae and total species richness, therefore red algae were not included in the analyses. A one-way analyses of variance (ANOVA) was performed for orientation and level to check for differences between the diversity variables considered. A t-test was run for light source to check for differences between diversity. Pairwise comparisons using t-test were applied between the categories of orientation and level once ANOVA yield significant differences. All the analyses were run as implemented in Statistica 7.

\section{RESULTS}

\subsection{Diversity of Phototrophic Biofilms}

The study of samples from the catacombs located in St Paul and St Paul and St Agatha has yield a preliminary list of 46 taxa, 21 of them have been identified only to genus level. Among the observed taxa, 27 belong to Cyanobacteria, 12 to green algae (Chlorophyta), 5 to diatoms (Bacillariophyta), and 2 to red algae (Rodophyta). Occasionally, there were protonemata of mosses and one lichen species that have not been included in the posterior comparisons.

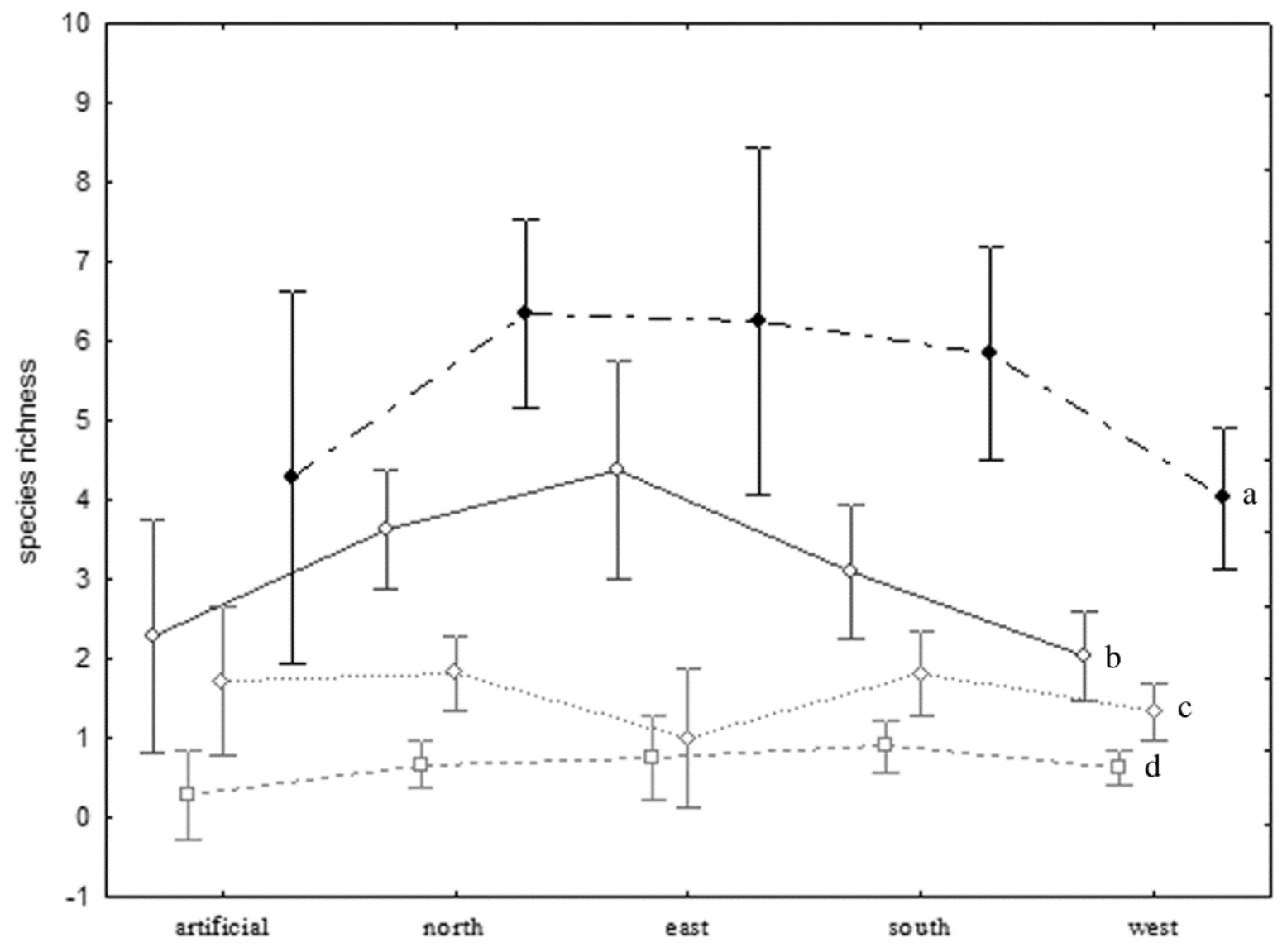

Figure 1. Distribution of total species richness (a) and species richness of components of phototrophic biofilms: cyanobacteria (b), green algae (c) and diatoms (d), from Maltese Catacombs depending on the orientation of catacomb, based on least squares means of ANOVA analyses. The central point corresponds to the mean and vertical bars denote the $95 \%$ confidence intervals. 

DOES LIGHT MATTER?

The predominant taxa at catacombs were Chroococcidiopsis spp (Cyanobacteria), Desmococcus olivaceus (Chlorophyta), Leptolyngbya nostocorum (Cyanobacteria), Diadesmis contenta (Bacillariophyta), and Muriella sp (Chlorophyta), which were present in more of the $30 \%$ of the samples. Three taxa related with our observations were previously recorded as predominant from several points from the main catacomb system at St Paul (Zammitt et al., 2011a).

\subsection{Comparison between Parameters Driving the Colonization of Catacombs by Phototrophic Biofilms}

The comparison of the effect of light on the composition of biofilms shows some differences between these samples growing in natural light from those growing in artificial light. However, the t-test analysis does not show any significant difference. Natural light enhances a richer community than artificial light. The different sampling effort does not provide enough data to have a complete look on colonization in areas with artificial light. The differences in light availability are not so significant between natural and artificial light to determine a shift in composition of biofilms. The cyanobacteria and green algae that predominate in these biofilms are able to colonize points with very low radiation (Albertano \& Bruno, 2003).

The orientation of catacomb and the location of biofilms inside the catacomb have low effect on the diversity of phototrophic biofilms. ANOVA analyses were not significant for both parameters. Catacomb orientation has a slight effect on cyanobacteria. Pairwise comparisons, applying t-test, between the richness of cyanobacteria between the bearings yields a significant difference. Samples taken from the west facing points within catacombs harbor a lower species richness of cyanobacteria than samples taken from any other bearing. This difference is greater when compared with samples from east facing catacombs (Figure 1). Green algae richness does not change so markedly, except for a slight decline on the east facing catacombs, despite it is not significant. Diatoms have no clear changes on their richness depending on the orientation of catacombs. The west orientation of catacombs is affected by other parameters other than light which determine the shifts on species richness of cyanobacteria. This specific bearing would modify the availability of liquid water, a key factor for the growth of cyanobacteria. Nonetheless, the lack of long-term monitoring of environmental parameters in these hypogea does not allow hypothesizing on which particular variables are driving biofilm colonization.

The species richness diversity declines when moving inside catacombs, but those changes do not have a statistically significant difference (Figure 2). In terms of the composition of biofilms, the colonization of inner areas of catacombs increases the importance of green algae, and reduces the presence of diatoms, while cyanobacteria are not affected (Figure 3). Otherwise, the reduction of available light limits the colonization of phototrophic biofilms, but the capability of cyanobacteria and green algae to make use of very low dose of visible radiation enhances their presence even in almost dark areas (Mulec et al., 2008; Albertano \& Bruno, 2003).

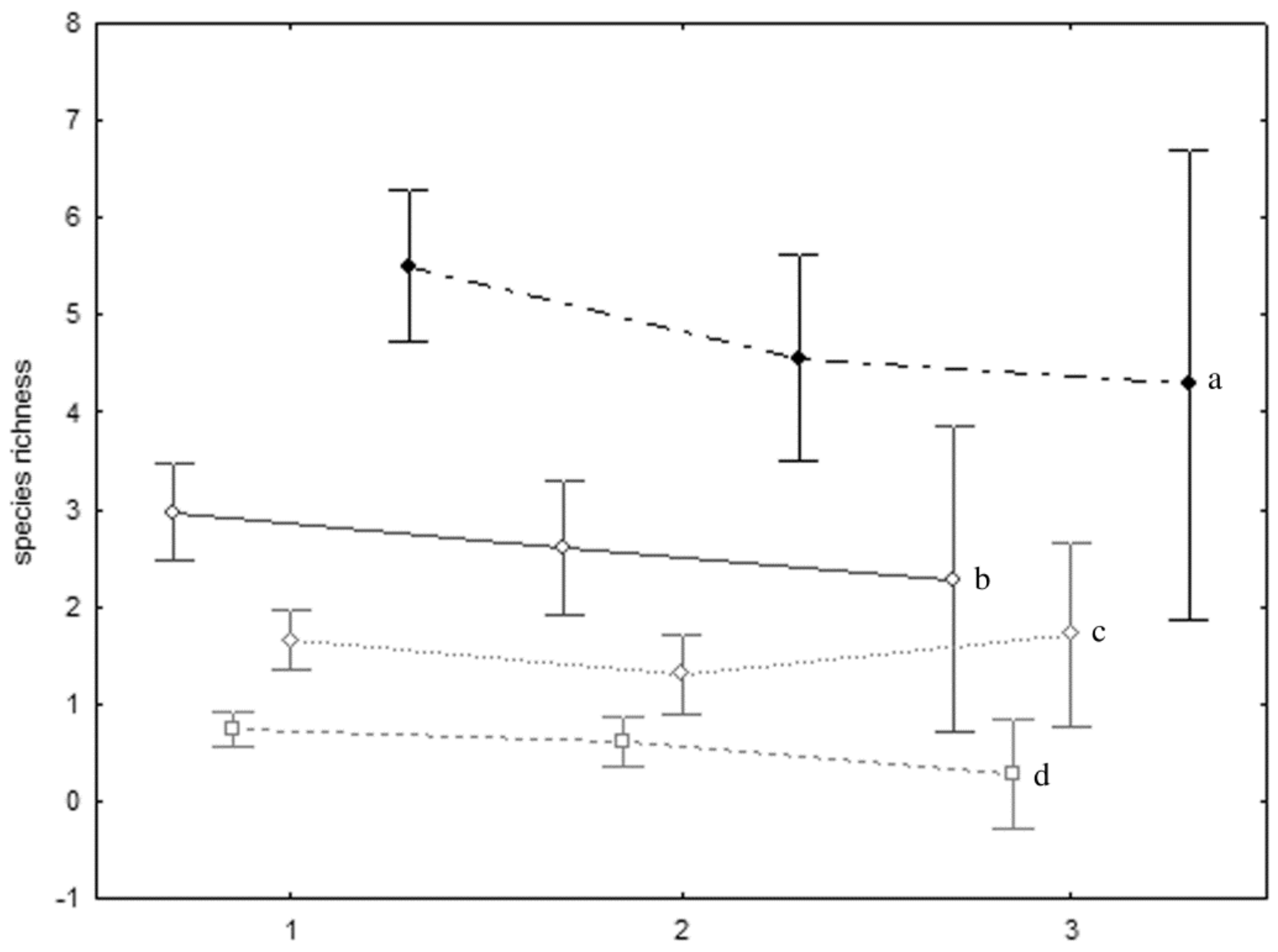

Figure 2. Distribution of total species richness (a) and species richness of components of phototrophic biofilms: cyanobacteria (b), green algae (c) and diatoms (d), from Maltese Catacombs depending on the location inside the catacomb, based on least squares means of ANOVA analyses. The central point corresponds to the mean and vertical bars denote the $95 \%$ confidence intervals. Location inside catacombs refers to entrance (1), inner hall (2) and dark areas (3). 


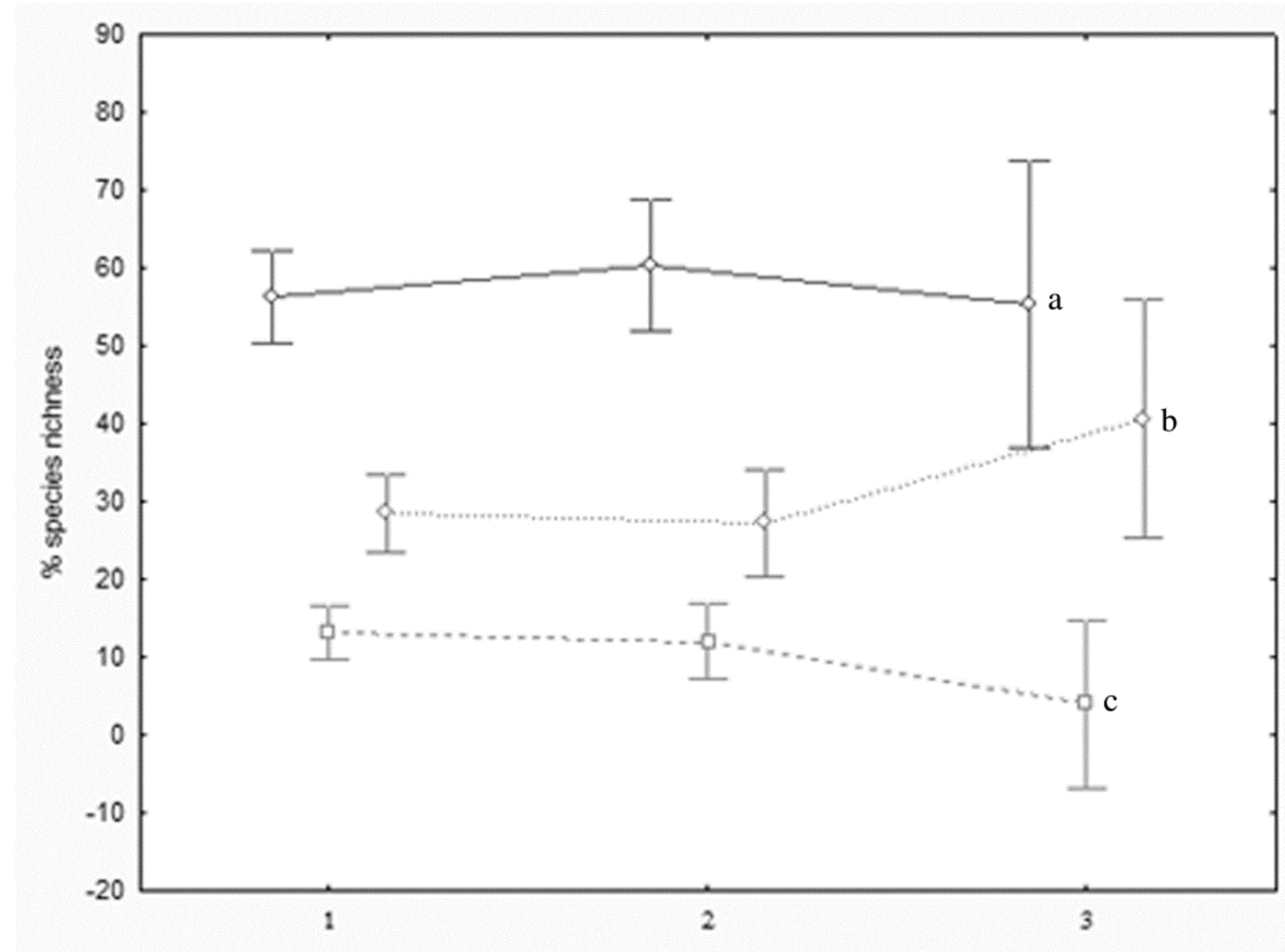

Figure 3. Distribution of the percentage of species richness for the main components of phototrophic biofilms: cyanobacteria (a), green algae (b) and diatoms (c), from Maltese Catacombs depending on the location inside the catacomb, based on least squares means of ANOVA analyses. The central point corresponds to the mean and vertical bars denote the $95 \%$ confidence intervals. Location inside catacombs refers to entrance (1), inner hall (2) and dark areas (3).

\section{CONCLUSIONS}

The distribution of phototrophic biofilms does not have a clear pattern derived from light availability; despite the fact that our data suggest that an increase in light intensity hinders the specific richness of cyanobacteria, as seen on south and west facing catacombs (Figure 1). Cyanobacteria prefer lower radiation than other phototrophic taxa, and they are better adapted to develop on such environments, due to their pigments (Albertano et al, 2005). An important point to keep in mind by curators taking care of these hypogea is that a pool of colonizing species is present which require small amounts of light to develop (Albertano \&, Bruno, 2003). Therefore, increasing visitors' accessibility within the catacombs by installing any source of artificial light would enhance an increase in surface biofilm colonization. In addition, some of the more common taxa are involved in mineral precipitation and other mineralization processes (Ariño et al., 1997; Albertano \& Urzi, 1999), which would promote biodeterioration of catacombs (Zammitt et al 2011a).

\section{REFERENCES}

Albertano, P., Bruno, L., 2003. The Importance of Light in the Conservation of Hypogean Monuments. C. Saiz-Jiménez (Ed.): Moleccular Biology and Cultural Heritage. Swets \& Zeitlinger BV, Lisse, pp. 171-177.

Albertano, P., Bruno, L., Bellezza, S., 2005. New strategies for the monitoring and control of cyanobacterial films on valuable lithic faces. Plant Biosyst. 139, pp. 311-322.

Albertano, P., Urzi, C., 1999. Structural interactions among epilithic cyanobacteria and heterotrophic microorganisms in Roman hypogea. Microb. Ecol., 38, pp. 244-252.

Ariño, X., Hernández-Mariné, M., Saiz-Jiménez, C., 1997. Colonization of Roman tombs by calcifying cyanobacteria. Phycologia, 36, pp. 366-373.

Guillitte, O., 1995. Bioreceptivity: a new concept for building ecological studies. Sci. Total Environ. 167, pp. 215-220.

Hernández-Mariné, M., Asencio-Martínez, A., Canals, A., Ariño, X., Aboal, M, Hoffman, L., 1999. Discovery of populations of the lime incrusting genus Loriella 
(Stigonematales) in Spanish caves. Arch. Hydrobiol. Algol. Stud. 94, pp. 121-138.

Mulec, J., Kosi, G, Vrhovýek, D., 2008. Characterization of cave aerophytic algal communities and effects of irradiance levels on production of pigments. J. Cave Karst Stud. 70, pp. 312 .

Ortega-Calvo, J. J., Ariño, X., Hernández-Mariné, M., SaizJiménez, C., 1995. Factors affecting the weathering and colonization of monuments by phototrophic microorganisms. Sci. Total Environ., 167, pp. 329-341.

Roldán, M, Clavero, E., Canals, A., Gómez-Bolea, A., Ariño, X., Hernãndez-Mariné, M., 2004. Distribution of phototrophic biofilms in cavities (Garraf, Spain). Nova Hedwig. 78, pp. 329351.

Sanchez-Moral, S., Luque, L., Cueva, S., Soler., Benavente, D., Laiz, L., González, J. M., Saiz-Jiménez, C., 2005. Deterioration of building materials in Roman catacombs: the influence of visitors. Sci. Total Environ., 349, pp. 260-276.

Warscheid, Th., Braams, J., 2000. Bioreceptivity of building stones. Int. Biodeterior. Biodegrad. 46, pp. 343-368.

Zammitt, G., Billi, D., Shubert, E., Kaýtovský, J., Albertano, P. 2011a. The biodiversity of subaerotrophic biofilms from Maltese hypogea. Fottea, 187, pp. 187-201.

Zammitt, G., Sánchez-Moral, S., Albertano, P., 2001b. Bacterially mediated mineralisation processes lead to biodeterioration of artworks in Maltese catacombs. Sci. Total Environ., 409, pp. 2773-2782.

\section{Acknowledgements}

This work was financed by Heritage Malta and the European Regional Development Fund (contract HM.04.11). 
